\title{
Variation of Natural Frequencies by Circular Saw Blade Rotation
}

\author{
Nikola ANĐELIĆ, Sanjin BRAUT, Ana PAVLOVIĆ
}

\begin{abstract}
In this paper the influence of circular saw blade rotation, slot shapes and number of slots on its natural frequencies and critical speeds is investigated. Firstly, the governing equation that describes the transverse vibrations of a stationary circular plate clamped at its centre is derived using Hamilton's principle and based on KirchhoffLove plate theory and von Karman strain theory. The results are then compared with the ones obtained using FEM method and the FEM method is then applied to the real circular saw blade model. Finally, influence of slot shapes and number of slots on natural frequencies and critical speeds is investigated.
\end{abstract}

Keywords: backward traveling wave; Campbell diagram; forward travelling wave; natural frequencies

\section{INTRODUCTION}

The circular plates are used in many industries and consumer tools and electronics such as circular saw blades, hard drives, CDs, DVDs, blue ray disks, etc. so detailed investigation of dynamic characteristics is necessary in order to prevent failure. The vibration analysis of spinning circular plates is a very complicated problem, which requires good understanding of physical phenomena in general, and good knowledge of mathematics in order to encapsulate and solve the problem. Kirchhoff developed the plate theory in order to investigate the free vibrations of spinning disks. In [1] the Kirchhoff analysis is extended to include rotational inplane stresses in case of freely spinning disks and in [2] this approach is applied to the analysis of centrally clamped disk. In [3] the analysis of circular disk clamped at its centre is carried out using the power-series solution of the Eigen functions. In [4] critical speeds are obtained for a uniform elastic disk at which a disk is unable to support arbitrary spatially fixed transverse loads. The effect of elastic foundation on vibrations of spinning disk is also investigated and showed that it raises the critical speed. In [5] the system of flexible spinning disk with a stationary load is analysed and derivatives of eigenvalues are obtained with respect to certain parameters in the system. In [6] the governing equation is derived that describes linear and nonlinear vibrations of spinning disk model and in [7] only linear transverse vibrations of spinning disk model are analysed.

In [8] the influence of slot length of rectangular shaped slots and heat caused by cutting on natural vibrations of circular saw blade is analysed. In [9] the numerical optimization of circular saw was carried out and among other things Southwell method was used in order to generate Campbell diagram.

In this paper the governing equation which describes free transverse vibrations of stationary circular plate clamped at its centre is derived using Hamilton's principle, based on Kirchhoff-Love plate theory and von Karman strain theory. This method is used in order to obtain the natural frequencies of circular plate and the results are compared to FEM model of circular plate. Since an analytical approach is appropriate for simple models such as circular plate for the analysis of circular saw blades it is better to use FEM method in order to obtain natural frequencies because of complex geometry. Finally, the influence of slot shape on natural frequencies and critical speed is investigated and for this analysis three commonly used slot shapes are modelled and these slot shapes are: rectangular, hook and S shaped slots. The influence of number of slots on natural frequencies and critical speeds is investigated.

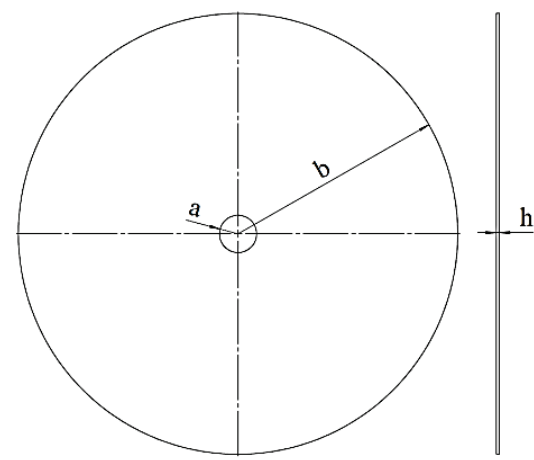

Figure 1 Circular disk clamped at inner radius

\section{VIBRATIONS OF STATIONARY CIRCULAR PLATES CLAMPED AT ITS CENTRE}

Circular saw blades are an assembly which consists of two parts: disk and teeth. For vibration analysis, the model can be simplified as a circular plate which is free on outer radius and clamped on inner radius. The circular disk clamped at its centre with inner radius $a$ and outer radius $b$ is shown in Fig. 1 .

The procedure of deriving differential equation is well documented in the literature [6] and [7] and consists of defining the terms for kinetic and potential energy. Depending on which forces act on the disk there are two terms inside the potential energy that is: strain energy or a work done by internal forces and the work done by external forces. If there are no external forces that are acting on circular plate then the strain energy is the only potential energy part. [6] concludes that strain energy is the same for stationary and spinning circular plate while the kinetic energy part is the one that makes major influence in developing the differential equation which describes the phenomenon of spinning disk. After the development of strain and kinetic energy, the terms are all put together in Hamilton's principle or principle of least 
action. In general, it is a variation of the Lagrangian function after which the following equation is derived:

$D \nabla^{4} w+\rho h \frac{\partial^{2} w}{\partial t^{2}}=0$

This equation describes the vibrations of stationary disk and will be enough for determining the starting point in Campbell diagram. If term $\nabla^{2}$ is treated as rectangular operator then this equation can be separated into two second-order differential equations (Helmholtz equations). The equations are solved using separations of variables and the resulting solution can be written in the following form.

$w(r, \theta, t)=\sum_{m=0}^{\infty} \sum_{n=0}^{\infty} W_{m, n}(r) \cos (n \theta) e^{i \omega_{m, n} t}$

where:

$$
\begin{aligned}
& W_{m, n}(r)=A_{m, n} J_{n}\left(\frac{\lambda_{m, n} r}{a_{2}}\right)+ \\
& B_{m, n} Y_{n}\left(\frac{\lambda_{m, n} r}{a_{2}}\right)+C_{m, n} I_{n}\left(\frac{\lambda_{m, n} r}{a_{2}}\right)+ \\
& D_{m, n} K_{n}\left(\frac{\lambda_{m, n} r}{a_{2}}\right),
\end{aligned}
$$

in which $n$ and $m$ represent the number of nodal diameters and circles, respectively. The coefficients $A_{m, n}, B_{m, n}, C_{m, n}$ and $D_{m, n}$ are the mode shape coefficients, which are determined by the boundary conditions. $J_{n}$ and $Y_{n}$ are the Bessel functions of the first kind and the second kind, respectively, while $I_{n}$ and $K_{n}$ are modified Bessel functions of the first and second kind, and $\lambda_{m, n}$ is the dimensionless frequency parameter which is also determined by the boundary conditions. The dimensionless frequency parameter is related to the natural frequency by:

$\omega_{m, n}=\frac{\lambda_{m, n}^{2}}{b^{2}} \sqrt{\frac{D}{\rho h}}$

In the case of the clamped inner edge, the boundary conditions are:

$$
\begin{gathered}
w=0 \\
\frac{\partial w}{\partial r}=0, \\
\text { at } r=a .
\end{gathered}
$$

The boundary conditions for the outer edge:

$M_{r}=-D\left(\frac{\partial^{2} w}{\partial r^{2}}+\frac{v}{r} \frac{\partial w}{\partial r}+\frac{v}{r^{2}} \frac{\partial^{2} w}{\partial \theta^{2}}\right)=0$,

at $r=b$, where $M_{r}$ and $M_{r \theta}$ are the bending and twisting moments and $Q_{r}$ is transverse shear force. In case of classical plate theory, the in-plane boundary conditions are not applied and have no effect on natural vibrations.
For this analysis, the AISI 304 material is used. The geometry parameters and material characteristics of annular plate are given in Tab. 1.

The calculation of the linear vibrations of circular plates clamped at their centres was carried out and the results of the analysis are shown in Tab. 2.

Table 1 Characteristics of annular plate

\begin{tabular}{|l|c|}
\hline \multicolumn{1}{|c|}{ Geometry and material characteristics } & Value \\
\hline Inner radius, $a / \mathrm{m}$ & 0.0127 \\
\hline Outer radius, $b / \mathrm{m}$ & 0.15 \\
\hline Thickness, $h / \mathrm{m}$ & 0.0022 \\
\hline Young's Modulus / GPa & 193 \\
\hline Poisson ratio & 0.29 \\
\hline Density / kg/m $\mathrm{m}^{3}$ & 8000 \\
\hline
\end{tabular}

Table 2 Frequency parameters for annular plate clamped at the inner edge and free on the outer edge

\begin{tabular}{|c|c|c|c|c|}
\hline$n$ & $m$ & $\lambda_{m, n}$ & $\omega_{m, n} / \mathrm{rad} / \mathrm{s}$ & $f_{m, n} / \mathrm{Hz}$ \\
\hline 0 & 0 & 2.03 & 598.29 & 95.21 \\
\hline 1 & 0 & 1.81 & 475.87 & 75.73 \\
\hline 2 & 0 & 2.36 & 808.12 & 128.62 \\
\hline 3 & 0 & 3.53 & 1811.9 & 288.38 \\
\hline 4 & 0 & 4.68 & 3177.47 & 505.71 \\
\hline 5 & 0 & 5.79 & 4872.76 & 775.44 \\
\hline 6 & 0 & 6.89 & 6889.63 & 1096.52 \\
\hline 0 & 1 & 4.93 & 3529.47 & 561.73 \\
\hline 1 & 1 & 5.17 & 3881.68 & 617.78 \\
\hline 2 & 1 & 6.04 & 5283.78 & 840.94 \\
\hline 3 & 1 & 7.29 & 7698.64 & 1225.28 \\
\hline
\end{tabular}

\section{MODELLING AND FEM ANALYSIS OF CIRCULAR SAW BLADES}

The vibration of circular saw blades represents a critical aspect for a safe and precise manufacturing [1013], especially in modern cutting tool processing, where uncommon materials [14] or controlling solutions [15] are frequently adopted. It can be investigated by Finite Element Method comparing simulations and measures. In several papers (as the previous [1-7]) the analysis of spinning circular saw blades is analysed using different numerical approaches and different types of loads acting on the systems. None of those papers compared natural frequencies with the frequencies obtained using a FEM method. In addition, it is very difficult to perform the analysis using rotor dynamics software such as Ansys, Femap NX Nastran [16, 17]. In rotor dynamics the Campbell diagrams are usually obtained using fixed reference frame since the most common analysed models are made from rotating and non-rotating parts. For the rotor dynamic analysis of structures such as hard disks, CDs, DVDs and circular saw blades the rotating reference frame is used since the whole structure is rotating. The problem arises in [18] detailing a procedure of obtaining Campbell diagram because some of commercial FEM software is unable to obtain critical speed of the rotating structure in rotating reference frame.

After modal analysis is carried out for a model of circular plate clamped at its centre using FEM method and the natural frequencies are obtained the results are compared with the previously used analytical model. Then the procedure of constructing Campbell diagram or diagram that shows the variation of natural frequencies by 
spinning speed applied on the circular disk clamped at its centre is extended to the real circular saw blades and investigation of slot shapes and number of slots on natural frequencies and critical speed is analysed.

\subsection{Modal Analysis of Stationary Circular Plate Clamped at Its Centre}

Modal analysis is used to determine the vibration characteristics such as natural frequencies and mode shape of a structure. For this analysis, the circular plate is modelled according to data presented in Tab. 1. To define the finite element model the element size is 0.001 and the plate elements are used to mesh the model. Since the disk is centrally clamped the constraints are applied to the inner radius of the circular plate. The results of eigenvalue analysis, obtained using the FEM method, are given in Tab. 3.

Table 3 Comparison of frequencies of annular plate using analytical and FEM method

\begin{tabular}{|c|c|c|}
\hline Mode shape $(m, n)$ & Analytical method & $\begin{array}{l}\text { Modal analysis } \\
\text { (FEM method) }\end{array}$ \\
\hline & \multicolumn{2}{|c|}{ Frequency / Hz } \\
\hline$(0,1)$ & \multirow{2}{*}{75.73} & 75.52 \\
\hline$(0,1)$ & & 75.52 \\
\hline$(0,0)$ & 95.21 & 94.99 \\
\hline$(0,2)$ & \multirow{2}{*}{128.62} & 128.35 \\
\hline$(0,2)$ & & 128.35 \\
\hline$(0,3)$ & \multirow{2}{*}{288.38} & 287.88 \\
\hline$(0,3)$ & & 287.87 \\
\hline$(0,4)$ & \multirow{2}{*}{505.71} & 504.51 \\
\hline$(0,4)$ & & 504.51 \\
\hline$(1,0)$ & 561.73 & 560.88 \\
\hline$(1,1)$ & \multirow{2}{*}{617.78} & 616.06 \\
\hline$(1,1)$ & & 616.07 \\
\hline$(0,5)$ & \multirow{2}{*}{775.44} & 773.11 \\
\hline$(0,5)$ & & 773.11 \\
\hline$(1,2)$ & \multirow{2}{*}{840.94} & 838.35 \\
\hline$(1,2)$ & & 838.36 \\
\hline$(0,6)$ & \multirow{2}{*}{1096.52} & 1092.48 \\
\hline$(0,6)$ & & 1092.49 \\
\hline
\end{tabular}

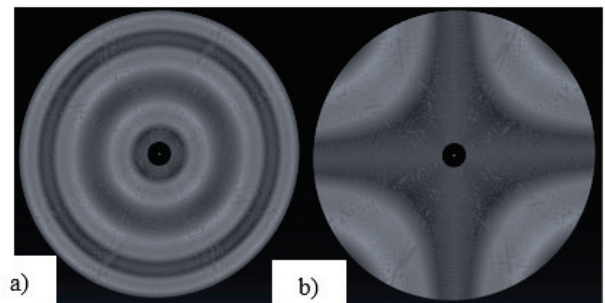

Figure 2 Modal shapes of circular disk: a) Nodal Circle and b) Nodal Diameters

In previous table, the number of nodal diameters and nodal circles defines the modal shapes. The nodal diameters are lines on circular plate, which remain stationary during the vibration cycle, and the nodal circles are concentric circles which remain stationary during the vibration cycle. The nodal circles and nodal diameters are shown in Fig. 2.

\subsection{Variation of Natural Frequencies by Circular Disk Rotation}

In this paper to obtain the Campbell diagram the FEM analysis is used to obtain natural frequencies for the stationary circular disk. After the natural frequencies are obtained they are categorized based on their nodal diameter and nodal circles. To construct Campbell diagram, based on literature [1, 2, 9] speed depending frequency, backward and forward traveling wave and critical speeds are calculated.

The speed depending frequency is calculated from the following expression:

$$
f_{e w}^{2}=f_{n}^{2}+\lambda \Omega^{2}
$$

where $\lambda$ is a factor that accounts for mode shape and can be calculated using the number of nodal diameters $n$ and the Poisson ratio $v$ as follows:

$\lambda=\frac{1-v}{4} n^{2}+\frac{3+v}{4} n$

Forward and backward traveling waves are calculated from the following expressions:

$$
\begin{aligned}
& f_{f}=f_{\text {ew }}+n \Omega, \\
& f_{b}=\left|f_{\text {ew }}-n \Omega\right| .
\end{aligned}
$$

The critical speed of each mode can be calculated using the following expression:

$$
f_{\text {crit }}=\frac{f_{\text {ew }}}{\sqrt{k^{2}-\lambda}} .
$$

Based on the previous expressions and the natural frequencies obtained using FEM method or analytical method the speed depending frequencies, forward and backward traveling waves and critical speeds are calculated and shown in Fig. 3 and Tab. 4. In Tab.4 index $f$ denotes forward travelling wave and the $b$ denotes backward traveling wave.

\subsection{Modal Analysis of Stationary Circular Saw Blade Clamped at Its Centre}

Today there are many types of saw blades and each saw blade is specially designed to provide the best results in a particular cutting operation. The saw blades are able to get specialized blades for ripping lumber, crosscutting lumber, cutting plywood and panels. As mentioned before circular saw blades are made of two parts the first part being circular disk, which is usually made from steel and the teeth, which are made of tungsten carbide or titanium carbide. In production of circular saw blades, the tungsten carbide and the circular disk are joined through the process of brazing.

Table 4 Critical speeds of an annular plate

\begin{tabular}{|c|c|}
\hline Mode shape & Critical speed $/ \mathrm{Hz}$ \\
\hline$(0,0)$ & $/$ \\
\hline$(0,1)$ & $/$ \\
\hline$(0,2)$ & 100.08 \\
\hline$(0,3)$ & 129.59 \\
\hline$(0,4)$ & 160.59 \\
\hline$(0,5)$ & 190.61 \\
\hline$(0,6)$ & 168.77 \\
\hline
\end{tabular}


The reason for using tungsten carbide or titanium carbide is that it will stay sharper longer than other materials and can be exposed to higher temperatures. There are also combination blades, which are designed to work in two or more types of cuts such as blades designed for crosscut and rip. General-purpose blades are designed as the name states for various types of cuts. Number of teeth plays important role in cutting operation. The blades with more teeth will give smoother cut while the blades with fewer teeth remove material much faster. Gullet is the space in front of each tooth to allow chip removal. When ripping the material, the feed rate is much faster so the chip size is much bigger and this demands that circular saw must have bigger gullets in order to handle a large amount of material. Crosscutting blades produce smaller chips so gullet is much smaller.

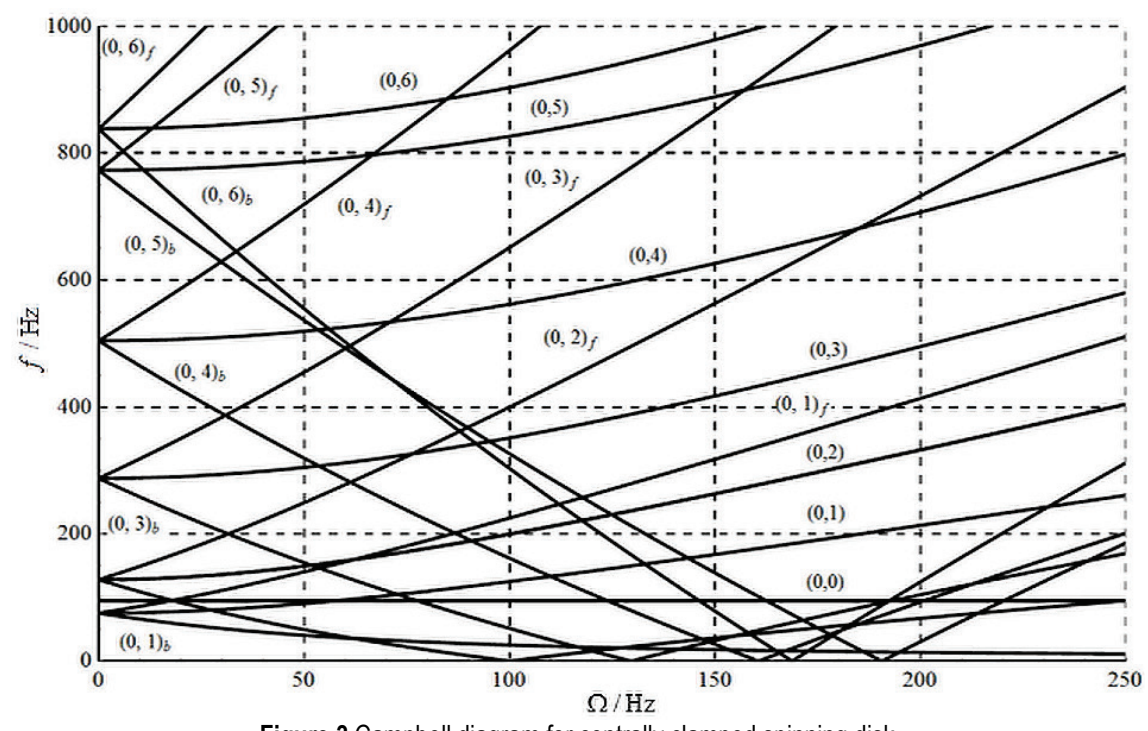

Figure 3 Campbell diagram for centrally clamped spinning disk

Table 5 Material characteristics of circular saw disk and teeth

\begin{tabular}{|c|c|}
\hline \multicolumn{2}{|c|}{ Geometric data of circular saw blade } \\
\hline Outer diameter/m & 0.3 \\
\hline Inner diameter $/ \mathrm{m}$ & 0.0254 \\
\hline Plate thickness $/ \mathrm{m}$ & 0.0022 \\
\hline Number of teeth/m & 48 \\
\hline Maximum thickness of teeth $/ \mathrm{m}$ & 0.0032 \\
\hline Hook angle $/{ }^{\circ}$ & 20 \\
\hline Clearance angle $/{ }^{\circ}$ & 15 \\
\hline Side clearance angle $/{ }^{\circ}$ & 5 \\
\hline Face bevel angle $/{ }^{\circ}$ & 2 \\
\hline Top bevel angle $/{ }^{\circ}$ & 5 \\
\hline Radial clearance angle ${ }^{\circ}$ & 4 \\
\hline \multicolumn{2}{|c|}{ Material characteristics for circular plate (AISI 304) } \\
\hline Young's modulus, $E / \mathrm{GPa}$ & 193 \\
\hline Poisson's ratio, $v$ & 0.29 \\
\hline Density, $\rho / \mathrm{kg} / \mathrm{m}^{3}$ & 8000 \\
\hline \multicolumn{2}{|c|}{ Material characteristics for teeth (Tungsten Carbide) } \\
\hline Young's modulus, $E$ /GPa & 669 \\
\hline Poisson's ratio, $v$ & 0.24 \\
\hline Density, $\rho / \mathrm{kg} / \mathrm{m}^{3}$ & 15700 \\
\hline
\end{tabular}

Circular saw blade is modelled according to data presented in Fig. 4 and Fig. 5 and in Tab. 5. From Tab. 6 it can be concluded that the analytical method used in this paper gives good results when compared with FEM method of centrally clamped circular disk. Although due to more complicated geometry of circular saw blade geometry greater deviation in natural frequency was expected, analytical results are in good agreement with the FEM results of circular saw blade.

The results of natural frequencies obtained using FEM method and analytical method are shown in Tab. 6.

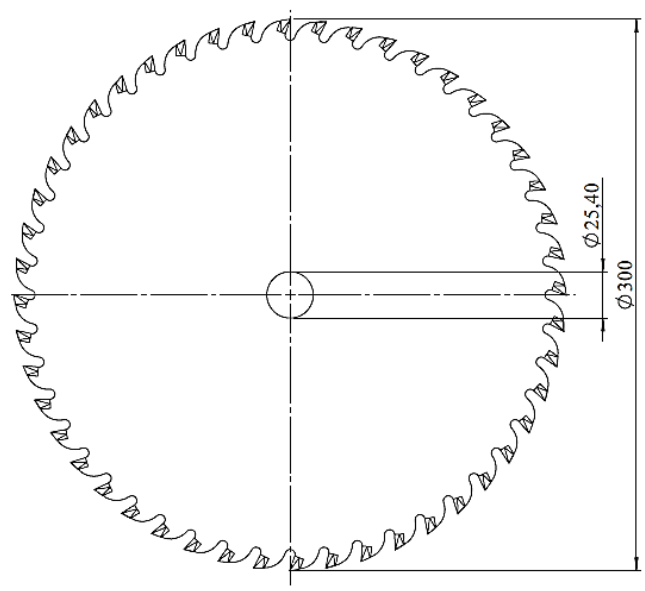

Figure 4 Geometry of circular saw blade (dimensions are in $\mathrm{mm}$ )

From Tab. 6 it is obvious that the first analytical method gives good results when compared to FEM method for annular plate and circular saw blade. Since the circular saw blade has more complex geometry, it is obvious that the frequencies will differ from circular plate and analytical method. After the natural frequencies are obtained for circular saw blade, the Campbell diagram can be constructed and critical speeds can be calculated based on Eqs. (9), (11), (12) and (13). The results are shown in Fig. 5 and Tab. 7. 


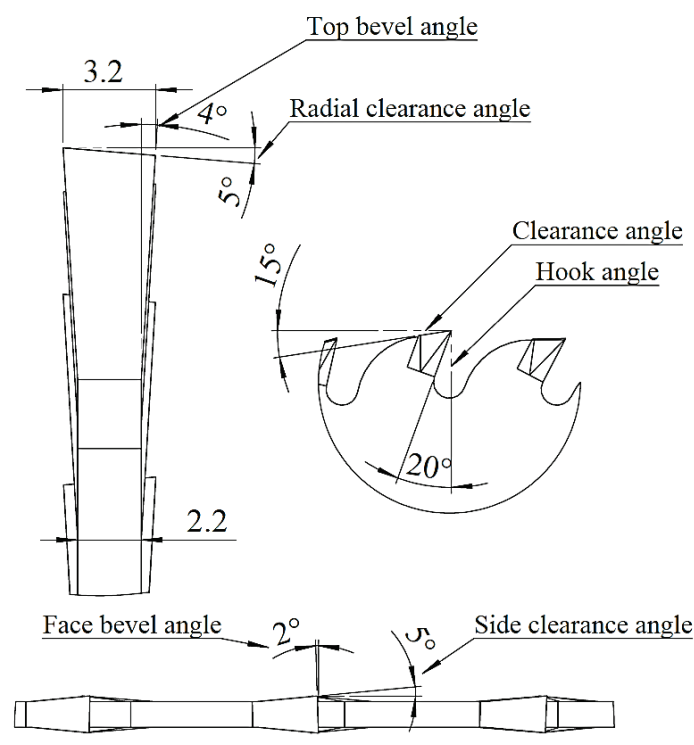

Figure 5 Teeth geometry of circular saw blade (dimensions are in $\mathrm{mm}$ )
Table 6 Comparison of natural frequencies between analytical and numerical FEM method

\begin{tabular}{|c|c|c|c|}
\hline $\begin{array}{l}\text { Mode } \\
\text { shape } \\
(\mathrm{m}, \mathrm{n})\end{array}$ & $\begin{array}{c}\text { Analytical } \\
\text { method for } \\
\text { circular plate }\end{array}$ & $\begin{array}{l}\text { Modal analysis of } \\
\text { circular plate } \\
\text { (FEM method) }\end{array}$ & $\begin{array}{l}\text { Modal analysis of } \\
\text { circular saw blade } \\
\text { (FEM method) }\end{array}$ \\
\hline$(0,1)$ & \multirow{2}{*}{75.73} & 75.52 & 77.26 \\
\hline$(0,1)$ & & 75.52 & 77.26 \\
\hline$(0,0)$ & 95.21 & 94.99 & 96.27 \\
\hline$(0,2)$ & \multirow[t]{2}{*}{128.61} & 128.35 & 126.97 \\
\hline$(0,2)$ & & 128.35 & 126.98 \\
\hline$(0,3)$ & \multirow{2}{*}{288.38} & 287.87 & 276.23 \\
\hline$(0,3)$ & & 287.88 & 276.24 \\
\hline$(0,4)$ & \multirow{2}{*}{505.71} & 504.51 & 471.76 \\
\hline$(0,4)$ & & 504.51 & 471.77 \\
\hline$(1,0)$ & 561.73 & 560.88 & 566.81 \\
\hline$(1,1)$ & \multirow{2}{*}{617.78} & 616.06 & 620.73 \\
\hline$(1,1)$ & & 616.07 & 620.74 \\
\hline$(0,5)$ & \multirow{2}{*}{775.44} & 773.10 & 705 \\
\hline$(0,5)$ & & 773.11 & 705.02 \\
\hline$(1,2)$ & \multirow{2}{*}{840.94} & 838.35 & 837.99 \\
\hline$(1,2)$ & & 838.36 & 838 \\
\hline$(0,6)$ & \multirow{2}{*}{1096.52} & 1092.48 & 971.46 \\
\hline$(0,6)$ & & 1092.49 & 971.51 \\
\hline
\end{tabular}

Table 7 Comparison of critical speed values of circular plate and circular saw blade

\begin{tabular}{|c|c|c|}
\hline Mode shape & $\begin{array}{c}\text { Critical speeds for } \\
\text { circular plate } / \mathrm{Hz}\end{array}$ & $\begin{array}{c}\text { Critical speeds for } \\
\text { circular saw blade } / \\
\mathrm{Hz}\end{array}$ \\
\hline$(0,0)$ & $/$ & $/$ \\
\hline$(0,1)$ & $/$ & $/$ \\
\hline$(0,2)$ & 100.08 & 99 \\
\hline$(0,3)$ & 129.59 & 124.35 \\
\hline$(0,4)$ & 160.59 & 150.17 \\
\hline$(0,5)$ & 190.67 & 173.82 \\
\hline$(0,6)$ & 168.7 & 168.7 \\
\hline
\end{tabular}

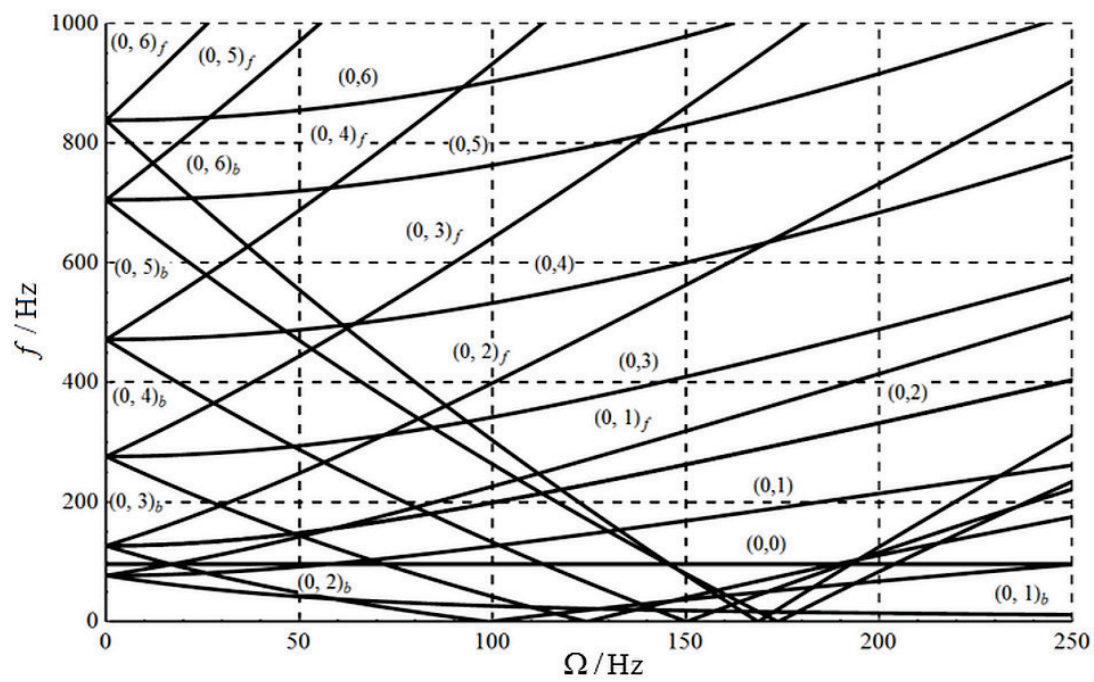

Figure 6 Campbell diagram for a circular saw blade without slots lower than the critical speeds of an annular plate due to different material and geometry.
For each investigation of a slot shape on natural frequencies and critical speeds the models of circular saw were created starting from a model without slots and then the model with 2, 3, 4, 6 and 8 slots. So there is total of 16 models of circular saw blade analysed. Applying the same procedure as before the natural frequencies are obtained for all models, Campbell diagrams are constructed and critical speeds are calculated. First, the influence of slot shape and number of slots on natural frequencies is investigated. In Fig. 8 the comparison of natural frequencies is shown. The influence of slot shapes and number of slots can be seen on higher natural frequencies i.e. mode shapes that have three or four nodal diameters. 
As seen in Fig. 8 and according to [8] denotation NT means nodal type and ANT means anti-nodal type. Nodal type is a type of mode shape in which nodal diameter goes through the slots and the anti-nodal type denotes type of mode shape in which nodal diameter is at angle with slots. In Fig. 9 the nodal and anti-nodal modal shapes are shown. The letter $R$ denotes the rectangular form of slot shape, $H$ denotes hook slot shape and the $S$ denotes the $S$ form of a slot shape.

In Fig. 8 only the lower natural frequencies are categorized because when analysing the model with multiple slots the mode shapes are difficult to categorize based on the number of nodal diameters and nodal circles. In Fig. 10 the complex mode shape is shown to illustrate the difficulty of determining the mode shape.

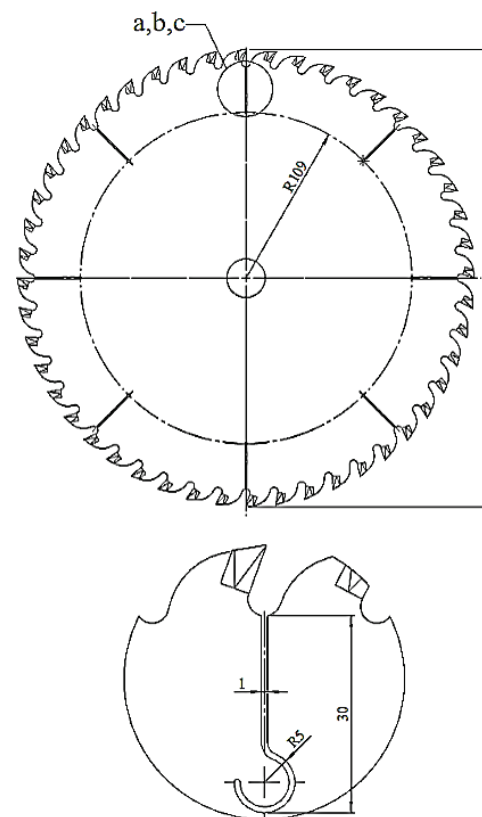

b)

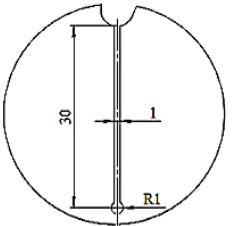

a)

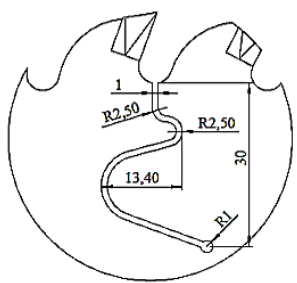

c)
Figure 7 Circular saw blade with a) rectangular slots, b) hook shaped and c) $S$ shaped slots

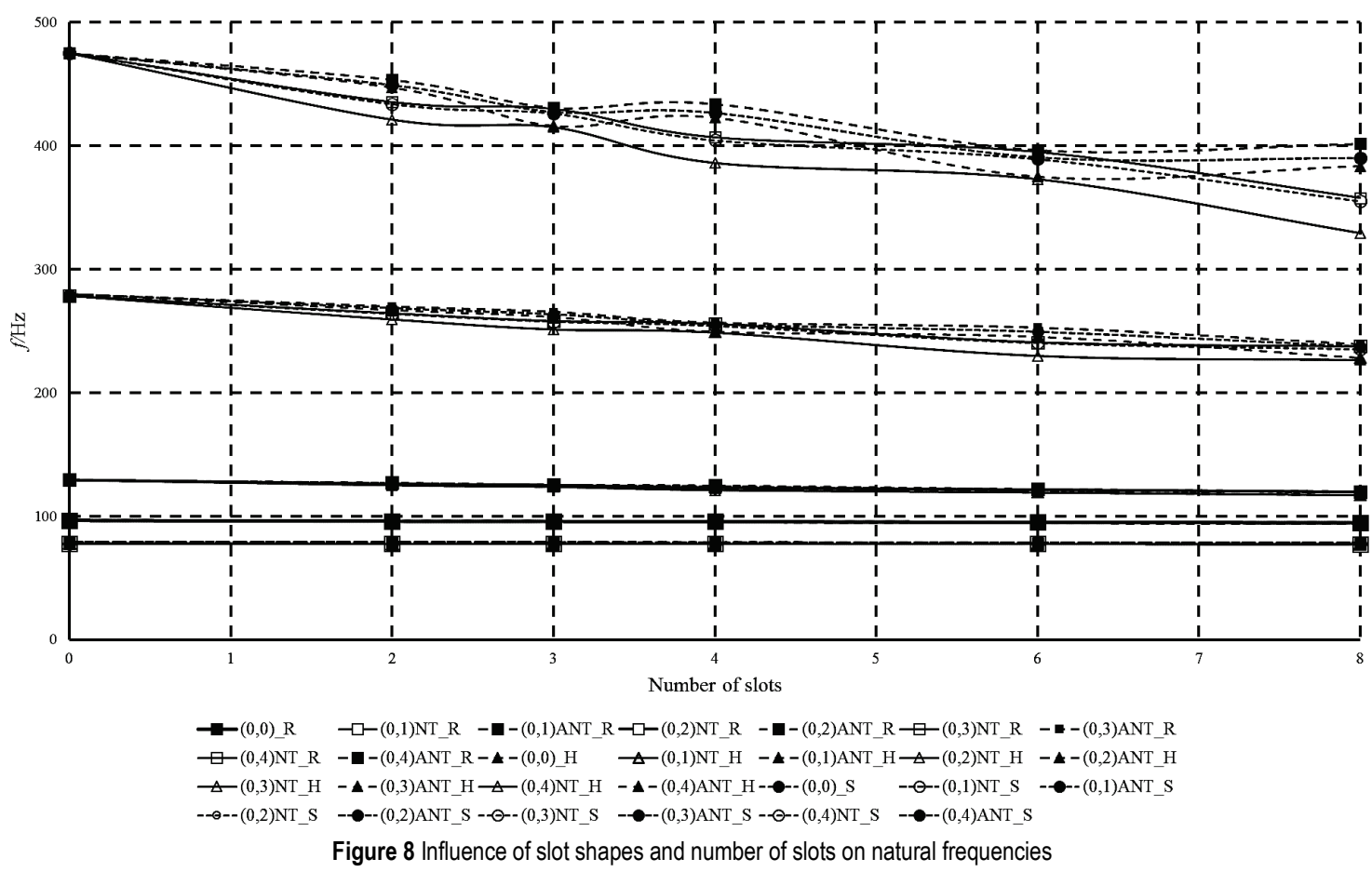

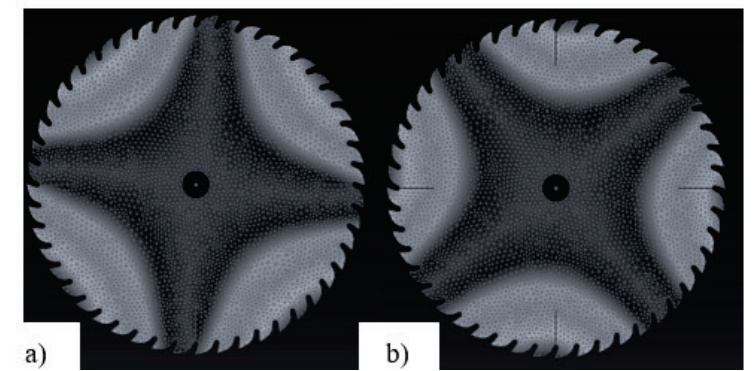

Figure 9 Circular saw blade with four rectangular slots a) nodal and b) antinodal modal shapes

Fig. 11 shows the influence of slot shapes and number of slots on critical speeds. For this analysis, the natural frequencies were obtained as before and then using Eq. (13) the critical speeds were calculated.

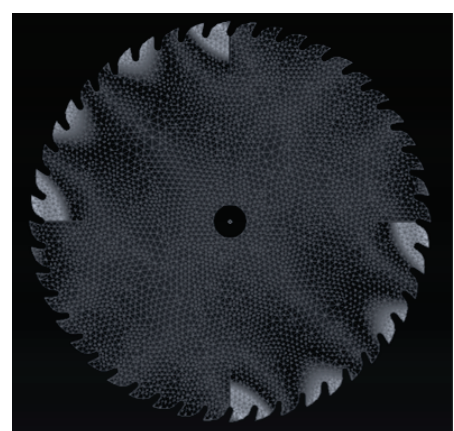

Figure 10 Complex mode shape 


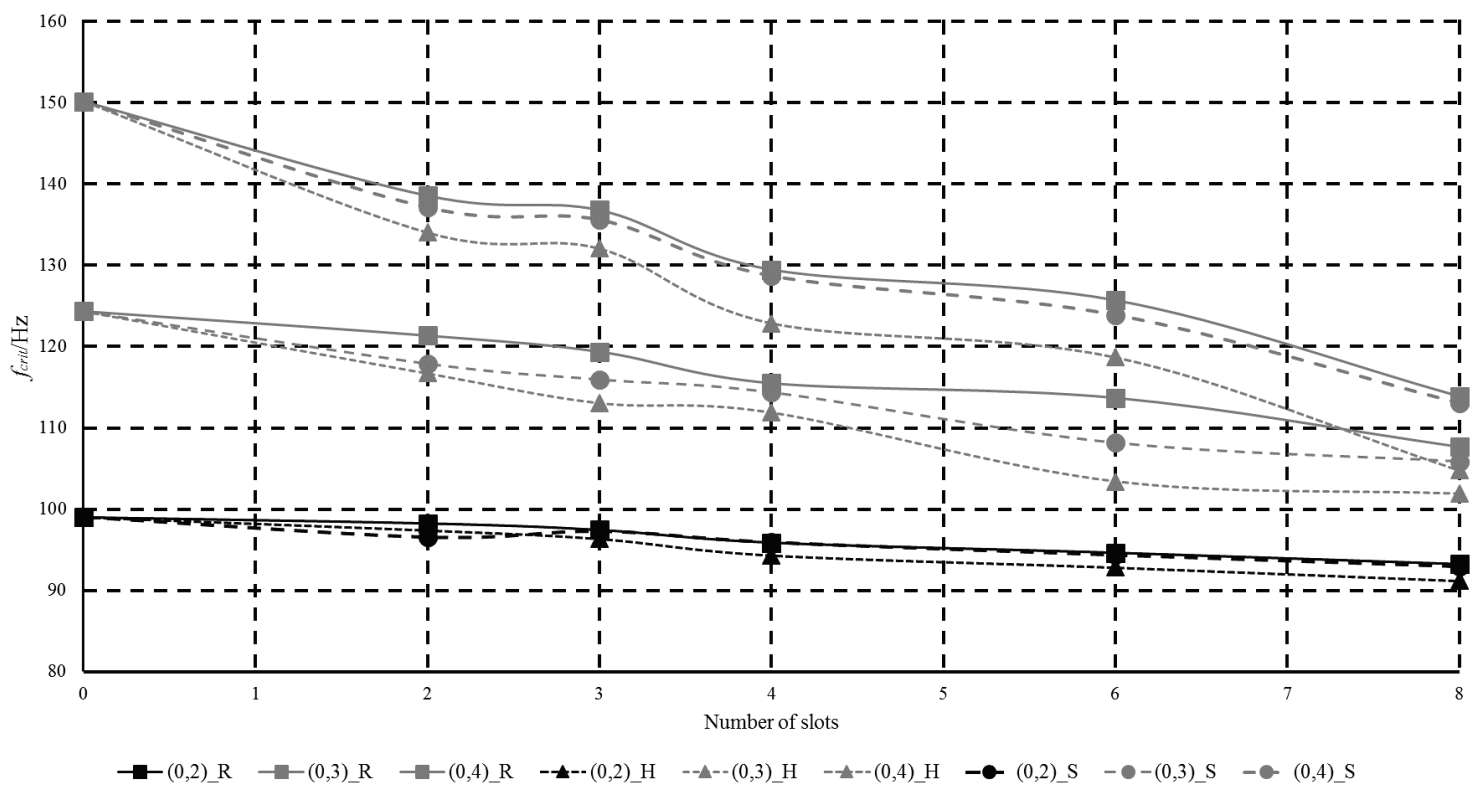

Figure 11 Influence of slot shape and number of slots on critical rotation speed

\section{CONCLUSION}

In this paper, the governing equation, which describes the free transverse vibrations of a stationary circular plate clamped at its centre, is derived using Hamilton's principle, based on Kirchhoff-Love plate theory and von Karman strain theory. It can be concluded that the analytical method here used provides valid results when compared with FEM method of centrally clamped circular disk as well as in the case of more complicated geometry of blades. It is noteworthy that the most common FEM software on the market is not able to offer appropriate results, even in the simple estimation of critical speeds. Therefore the following procedure for calculation is proposed: first natural frequencies obtained by FEM method are used as a starting point and then the influence of the rotational speed on natural frequencies is investigated following the procedure detailed in [18].

The influence of three different slot shapes and the number of slots on natural frequencies and critical speeds is also investigated. For this purpose 16 models of circular saw blades with different slot shapes such as rectangular, hook and S-shaped slots, as well as number of slots are analysed. Using greater number of slots in circular saw blade decreases the values of natural frequencies as well as critical speeds. Additionally the analyses showed that the most influential slot shape on natural frequencies and critical speeds is hook shaped slots.

This research can be extended involving relevant aspects as the nonlinear vibrations of woodworking band saws [19], with the general aim at providing a technical overview on circular saw blades in woodworking industry [20].

\section{Acknowledgments}

This investigation has been implemented as part of the activity inside the "AdriaHub - Bridge technical differences and social suspicions contributing to transform the Adriatic area in a stable hub for a sustainable technological development" project [20]. This action is co-funded by the European Union by the Instrument for Pre-Accession Assistance (IPA) on Adriatic Territory.

\section{REFERENCES}

[1] Lamb, H. \& Southwell, R. V. (1921). The Vibrations of a Spinning Disk. Proc. R. Soc. Lond. 99, 272-280. https://doi.org/10.1098/rspa.1921.0041

[2] Southwell, R. V. (1922). On the free transverse vibrations of a uniform circular disk clamped at its center and on the effects of rotation. Proc. R. Soc. Lond. 101, 133-153. https://doi.org/10.1098/rspa.1922.0032

[3] Dodson, R. O. Jr. \& Eversman, W. (1969). Free vibration of a centrally clamped spinning circular disk. AIAA Journal, 7(10), 2010-2012. https://doi.org/10.2514/3.5495

[4] Adams, G. G. (1987). Critical speeds for a flexible spinning disk. Int. J. Mech. Sci., 29(8), 525-531. https://doi.org/10.1016/0020-7403(87)90024-5

[5] Chen, J. S. \& Bogy, D. B. (1992). Effects of load parameters on the natural frequencies and stability of a flexible spinning disk with a stationary load system. Journal of Applied Mechanics, 59, S230-S235. https://doi.org/10.1115/1.2899494

[6] Baddour, N. \& Zu, J. W. (2001). A revisit of spinning disk models. Part I: derivation of equations of motion. Applied Mathematical Modeling, 25, 541-559. https://doi.org/10.1016/S0307-904X(00)00065-2

[7] Baddour, N. \& Zu, J. W. (2001) A revisit of spinning disk models. Part II: linear transverse vibrations. Applied Mathematical Modeling, 25, 561-578. https://doi.org/10.1016/S0307-904X(00)00066-4

[8] Nishio, S. \& Marui, E. (1996). Effects of Slots on the Lateral Vibration of a Circular Saw Blade. Int. J. Mech. Tools Manufact., 36(7), 771-787. https://doi.org/10.1016/0890-6955(95)00088-7

[9] Weiland, S. \& Birenbaum, C. (2014). Optimization of geometric features of circular saw blades and parameters of the manufacturing process aided by optislang. Weimarer Optimierungs- und Stochastiktage, 1-21.

[10] Lucisano, G., Stefanovic, M. \& Fragassa, C. (2016). Advanced Design Solutions for High-Precision Woodworking Machines. International Journal of Quality Research, 10, 143-158. 
[11] Fragassa, C. (2016). Material selection in machine design: the change of cast iron for improving the high-quality in woodworking. Proceedings of the Institution of Mechanical Engineers, Part C: Journal of Mechanical Engineering Science. March 2016. https://doi.org/10.1177/0954406216639996

[12] Pavlovic, A. \& Fragassa, C. (2016). Analysis of flexible barriers used as safety protection in woodworking. International. Journal of Quality Research, 10, 71-88.

[13] Pavlovic, A. \& Fragassa, C. (2016). Numerical modelling the ballistic impacts on flexible curtains used as safety protection in woodworking. Proceedings of the Institution of Mechanical Engineers, Part C: Journal of Mechanical Engineering Science. April 2016. https://doi.org/10.1177/0954406216646401

[14] Fotouhi, M., Saghafi, H., Brugo, T., Minak, G., Fragassa C., Zucchelli, A. \& Ahmadi, M. (2016). Effect of PVDF nanofibers on the fracture behaviour of composite laminates for high-speed woodworking machines. Proceedings of the Institution of Mechanical Engineers, Part C: Journal of Mechanical Engineering Science. 1989-1996 (vol. 203210). May 2016 https://doi.org/10.1177/0954406216650711

[15] Fragassa, C., Berardi, L. \& Balsamini, G. (2016) Magnetorheological fluid devices: an advanced solution for an active control on the wood manufacturing process. FME Transactions, 44(4), 333-339. https://doi.org/10.5937/fmet1604333F

[16] ANSYS, INC. Mechanical User Guide http://148.204.81.206/Ansys/150/ANSYS\%20Mechanical\% 20Users\%20Guide.pdf

[17] NX Nastran Rotor Dynamics User Guide https://docs.plm.automation.siemens.com/data_services/res ources/nxnastran/10/help/en_US/custom/rotordynamics/rot ordyn.pdf

[18] Skoblar, A., Andjelic, N. \& Zigulic, R. (2016) Determination of critical rotational speed of circular saws from natural frequencies of annular plate with analogous dimensions. International Journal of Quality Research, 10, 177-192.

[19] Fragassa, C. \& Zigulic, R. A practical guideline for the design and use of tools in woodworking. Tehnički vjesnikTechnical Gazette, (in print).

[20] Zigulic, R., Fragassa, C. \& Skoblar, A. (2017). Influence of the longitudinal displacement on nonlinear principal parametric resonance of the woodworking bandsaw. Tehnički vjesnik-Technical Gazette, 24(1), 253-263. https://doi.org/10.17559/TV-20160209175450

[21] Savoia, M., Stefanovic, M. \& Fragassa, C. (2016). Merging technical competences and human resources with the aim at contributing to transform the Adriatic area in a stable hub for a sustainable technological development. International Journal for Quality Research, 10, 1-16.

\section{Contact information:}

Nikola ANĐELIĆ, PhD student

Department of Mechanical Engineering,

Faculty of Engineering Rijeka, University of Rijeka

Vukovarska 58, 51000 Rijeka, Croatia

nandjelic@riteh.hr

\section{Sanjin BRAUT, Prof. PhD}

Department of Mechanical Engineering,

Faculty of Engineering Rijeka, University of Rijeka

Vukovarska 58, 5100 Rijeka, Croatia

sbraut@riteh.hr

\section{Ana PAVLOVIĆ, PhD}

Department of Industrial Engineering,

University of Bologna

Viale Risorgimento 2, 40136 Bologna, Italy

ana.pavlovic@unibo.it 